\title{
Classification of Sciences in the Works of Abu Raykhan Beruniy
}

\author{
Khandamova Marifat Akramovna, Turobov Bekpulat Nusratullayevich \\ Department of Social Sciences, Samarkand State Institute of Foreign Languages, Samarkand, Uzbekistan \\ Email: bekpulat2010@mail.ru
}

How to cite this paper: Akramovna, K. M., \& Nusratullayevich, T. B. (2020). Classification of Sciences in the Works of Abu Raykhan Beruniy. Open Journal of Philosophy, 10, 411-416.

https://doi.org/10.4236/ojpp.2020.103027

Received: April 14, 2020

Accepted: August 25, 2020

Published: August 28, 2020

Copyright (๑) 2020 by author(s) and Scientific Research Publishing Inc. This work is licensed under the Creative Commons Attribution International License (CC BY 4.0).

http://creativecommons.org/licenses/by/4.0/

\begin{abstract}
The development of all branches of science in Central Asia in the IX - XI centuries. The great thinkers of this period, such as Abu Bakr Razi, Abu Nasr Farabi, Ibn Sina and Beruniy, made a great contribution to the development of the sciences. There are quotations from the works of the scientist and scientific conclusions are given.
\end{abstract}

\section{Keywords}

Renaissance, Geodesy, Science, Astrology, Music, Geometry, Classification of Sciences, Logic, Philosophy

\section{Introduction}

The development of all branches of science in Central Asia in the IX - XI centuries. The great thinkers such as Abu Bakr Razi, Abu Nasr Farabi, Ibn Sina and Beruniy contributed greatly to the development of science. In the early medieval culture, all sciences were divided into two parts. These include Islamic sciences, Shari'a, that is, ulum al-Islam, or which mainly base on the problems relevant to poverty and sciences, will constitute the fundamental main aims of the article. In that case the science that is based on reason.

Abu Raykhan Beruniy's achievements in the field of special sciences have had a significant influence on his philosophical views as well. According to the scientist, the efforts of people to acquire true knowledge constitute their natural features. In their practical activities, they seek to understand the phenomena of nature that have not been revealed so far, either directly or indirectly by human beings. However, this does not mean that the knowledge of the mysteries of human nature is independent. The purpose of this is to make people use their knowledge as much as possible in their practical activities. Beruniy resisted the 
idea of chemists (alchemists) and astrologers who abandoned scientific research methods and condemned them for his scientific work. In his view, “... unless it was based on science, it would have to be abandoned” (al-Bayhaqiy, n.d.).

Although Beruniy did not write a particular work on the classification of sciences, but his deeper study reveals that he has focused on this issue. The scientific article addresses this issue in some of Beruniy's works.

As Abu Raykhan Beruniy has said in his famous work "Osor al-Boqiya", every science and art has its starting point. As you approach this beginning, it becomes simpler until you get to it (Beruniy, 1968).

In his book "Geodesy", the thinker describes the conflict between science and ignorance, "Their noble people think that it is misguided to ignore those who are like [science] in ignorance, to open the door to the loss of knowledge, and the collapse of scientists, with the aim of concealing their position with the secrets of knowledge" (Beruniy, 1982).

\section{Experimental Details}

Beruniy's ideas about learning are remarkable, and he says, "Science is desirable in its own way. Indeed, it is the most delicious of all. What is more profitable and more profitable than knowledge? It is only by knowledge that good deeds can be avoided and harmed by the world. Were it not for knowledge, we would not have been convinced that what we [are] attracting is not evil and that what is avoiding is not good" (Beruniy, 1982).

Also, reflecting on the socialization of science as a material necessity, I emphasize, "As far as science is concerned, human beings are able to respond to their nature by the nature of their service to the world". Because of the [human] needs and the low level of contentment and the absence of defensive weapons, despite the presence of many enemies, he was compelled to come together in order to help one another like him and to provide them with adequate service to him and others (Beruniy, 1982).

In his materialist position on the origins and functions of the Beruniy' sciences, he shows that the emergence of specific sciences was caused by the need for measuring the surface of various forms, the calculation of inheritance and property. A number of other disciplines also prove that they were formed and formed by material, vital needs and causes, and come to the following conclusions.

According to the thinker, there is a need in the daily life of calculations and surfaces when transferring wealth, land or surpluses from someone else's property to their own property, or to distribute them to their partners or to inherit them. These [calculations and surface measurements] form the basis of the two types of knowledge called mathematics and teaching. Their practical application is the science of geometry. This is the benefit of science (Beruniy, 1982). Here, he argues that the origin of science is an important factor in human development and community development. This means that science serves human needs and 
is a vital necessity.

After all, [a person] is breathing the air of various disasters, eating water and plants whose properties and qualities are changing, facing various celestial and terrestrial events that come from him, and from the inside, and can reject some of them. Since the opposite was intended for himself, experiments and comparisons led to the laying of the foundations of medical and veterinary science. As the days progressed, human thinking and physics became more profitable, which [science] would benefit humans and most animals, even though his knowledge was beyond the reach of absolute knowledge.

In emphasizing the social importance, he emphasized the inclination of the ignorant to superstition, and the fact that falsehood vanishes like a foam on the surface, and has proved the validity of these ideas in various works and events.

The philosopher's versatility is reflected in the fact that he focuses on music and the arts, along with his natural science, and expresses his views on it. In his writings, he promotes the idea that man's happiness and virtue are scientific, and he describes this phenomenon in music as "Geodesy" as follows.

The tone, if it is well-arranged, will have a profound effect on the heart-after all, he is the recipient of the discipline. Even in poetry, he found [the tone] because of the intensity of his order. The soul is more susceptible to the melody [of poetry], because it combines the tone of the song with the order of the poem. So mathematicians created a science [in science] in which he explained the basics of his principles, and he came to be known as "science music" (Beruniy, 1982).

In the Middle Ages, along with other sciences, music was developed. It can be seen that its development was influenced by local traditions by the Hellenistic period culture. The works of ancient Greek thinkers were also strongly influenced by the inclusion of music in the mathematical sciences and called it "Harmonica". This tendency can be traced back to Beruniy's thoughts. He tried to explain music science as a separate discipline and to explain it in mathematical form.

Beruniy says: "Since man has the ability to learn, he has been trying hard to find out what is missing. He was trying to find out about his future, in order to be alert to [various future] disasters and to be vigilant enough to repel them. On top of that, there were seasons when the sun was exposed to air, and the effects of the moon on the seas and dampness alternated between the quarter and the day and night. As a result of these [observations], his experience increased, and [the person] switched from these two [lamps] to the comparison of other lamps. As a result, it was the art of attacking its rules ..." (Beruniy, 1968). Here, Beruniy illustrates the growing need for scientific knowledge of the cracks in the sky, the increase in trade in the Middle Ages, the opening of commercial and maritime routes.

The thinkers of the ancient Greek philosophy, of course, needed a study of logic. They have realized that this is a wise way to know. Although Beruniy's works do not divide the classification of sciences into separate branches, they are 
logically described. In his definition of logic below, he tried to show that the concept of "criterion" is related to language, speech, poetry, and prose.

The man needed a "criterion" in his speech because he had a speech and debated with his opponents about world and Hereafter. This is because of the misleading lies of the syllogisms created by the words (the words) and the truth-revealing lies. Man has found this "criterion". It is called logic. Without knowing the logic. How marvelous is he who hates him and calls him by strange terms! Had he abandoned his laziness and read the words of rhyme, obscenity, and logic that would have been interrupted, he would have known that words, prose, prose and poetry would be broken. Nahw has been two clear criteria for correcting and correcting the error of the word [spoken] in prose and foreground, but these are the more common of the two, because it combines both prose and poetry (Beruniy, 1982).

Beruniy's profound knowledge of not only logic but also the literary Arabic language and grammar testifies to his open-mindedness in this field. We know that the development of Arabic grammar was strongly influenced by linguistic schools in Basra and Kufa, Iraq. They have done much to develop the theoretical issues of Arabic language and grammar (Bahodirov, 1995).

Beruniy emphasized that the Arabic language is an international language for the East: they were colorful and pleasing to the heart, and every nation believed that its language was beautiful, but the beauty of that language was everywhere (Bulgakov, 1972).

Beruniy expressed in his own view that the origin of the science of logic and the prose and prose are inseparable parts of it. Grammar regulates prose speech. In poetry and prose, he said that the true essence of the speech was its content (Kayumov, 1973).

While reflecting on the causes of the emergence of science, he analyzed the socio-philosophical nature of the sciences. This is the state of knowledge. They are the result of the essential needs of human life, and are thus divided into networks. The need for knowledge is in their interest, but not in silver and gold. [3; 65] defined the origins and objectives of the sciences of that time. Science has proven that nothing can be measured by wealth. The scientist argues that science has more social significance than material gain.

Beruniy said that language is a weapon of communication and a means of communication: "I once met a linguist at a meeting where the book of roads and countries was being discussed. The linguist was so humiliated that he was even expelled from a certain science. He used the words of his own words to help us realize that it is useless to find the distance between countries. Even though it was not amazing, I was astonished because it is better to limit one person to another without the presence of others, even if they do not have a disposition regarding wishes and wishes. This [linguist] opposes him and prefers the Persian, and says to him". What is the benefit of the Lord on the shelf, in the lineage of the filler, and in the cause and splendor of the tongue in you? I don't need 
Arabic! "There is no [difference] between any of our contemporaries. His statement is [only] true to himself, but not absolutely" (Beruniy, 1982).

In his book, India, Beruniy proposes that there is a great deal of knowledge that can be multiplied by the fact that they are more successful in time and different thoughts and memories come together. "It is a sign of success that people are motivated by science and respect for science and the people of knowledge. Respecting the people of knowledge, especially of the rulers, causes an increase in various kinds of knowledge. This is because the ruler will free the hearts of the people of this world from pursuing their daily affairs. It is also the cause of the increase of knowledge that the ruler is praising and enjoying the knowledge of the rulers. So the hearts of men were created to love it and to hate the opposite".

\section{Results and Discussion}

The thinker emphasizes the moral and humanistic importance of learning: "Gaining salvation through knowledge is only through the avoidance of evil. Though there are many branches of evil, their foundations are greed, wrath, and ignorance" (Mets, 1966).

Among the works of Beruniy is also the work of Tahfim ("Understanding the Primary Data from the Science-iujum"). This work appears in two languages. There are 23 manuscripts in Arabic and Persian in the manuscript treasures of the world. The data from the above data indicate that the medieval was very popular.

According to K. Munirov, as a result of studying the books of Beruniy's "Tahfim" in the catalogs of the Oriental Manuscripts, he stated that the Tashkent copy of this work is one of the oldest in the world (Munirov, 1973).

\section{Conclusion}

The work, though devoted to astrology, contains a classification of sciences in essence and is written as a textbook giving initial insights into such subjects as arithmetic, geometry, astronomy, geography and chronology. This work consists of 530 questions and answers and seven chapters. This work is still relevant today, as the teaching of the disciplines uses pedagogical skills, unique teaching methods, and as Beruniy puts it in his own experience, the creative approach to the matter is illustrated in the following example. In the preface of his work, he wrote: "I wrote this work in the form of questions and answers at the request of Rayhan, daughter of Hasan of Khorezm, to be easy to understand". Beruniy's "Tahfim" was classified as $420 / 1029$, which is contained in the introduction to the following disciplines: "I started with geometry. Then I wrote about count and number, then the appearance and structure of the Universe, and then astrology. Because those who have not mastered these four disciplines will not be called astrologers" (Beruniy, 1975).

Academician Yu Krachkowski commented on Tahfim's work. “... it is a large encyclopedia explaining important issues and terms in geometry, arithmetic, as- 
tronomy, but astrology is one of his most famous works" (Krachkovsky, 1957).

\section{Acknowledgements}

It is clear from the above points that in his works, Abu Raykhan Beruniy also touched upon the science and scientific views, on the classification of sciences, on their philosophical and social significance, that's to say, on their epistemological features. This indicates the broader viewpoint of the thinker and the encyclopedic thinking.

\section{Conflicts of Interest}

The authors declare no conflicts of interest regarding the publication of this paper.

\section{References}

al-Bayhaqiy, A. H. (n.d.). Tatimma sivan al-hikma. Manuscript of the Abu Rayhan Beruni Institute of Oriental Studies in the Academy of Sciences of the Republic of Uzbekistan. Inv. No. 1448.

Bahodirov, R. M. (1995). From the History of Abu Abdullah al-Khwarizmi and the Classification of Sciences. Tashkent.

Beruniy, A. R. (1968). Selected Works. Tom I. (p. 63). Tashkent “Fan”.

Beruniy, A. R. (1975). Selected Works. T.VI. Tashkent.

Beruniy, A. R. (1982). Selected Works, III, Geodesy. The Author of the Introduction, Translation and Comments Is A. Akhmedov. Tashkent.

Bulgakov, P. G. (1972). Life and Work Beruniy. Tashkent.

Kayumov, A. (1973). Beruniy and Poetry. To the 1000th Anniversary of Beruniy's Birth. (p. 65). Tashkent.

Krachkovsky, I. Y. (1957). Selected Works, M-L., Publishing House of the USSR Academy of Sciences.

Mets, A. (1966). Musulmanskiy Renrssans. Moscow: Nauka.

Munirov, K. (1973). About the Tashkent Manuscript of "Tahfim". To the 1000th Anniversary of Beruniy's Birth. Collection of Articles. Tashkent. 